\title{
Experimental analysis of an automotive thermoelectric generator under different engine operating regimes
}

\author{
A. Massaguer ${ }^{1}$, E. Massaguer ${ }^{2}$, M. Comamala ${ }^{1}$, A. Cabot ${ }^{3}$, J. Ricart $^{1}$ and A. Deltell ${ }^{1}$ \\ ${ }^{1}$ Department of Mechanical Engineering and Industrial Construction \\ Polytechnic High School, University of Girona \\ Campus de Montilivi, 17003 Girona (Spain) \\ Phone/Fax number:+0034 972 419654, e-mail: albert.massaguer@udg.edu \\ ${ }^{2}$ NABLA Thermoelectrics S.L. \\ Campus de Montilivi, 17003 Girona (Spain) \\ Phone/Fax number:+0034 972 418377, e-mail: info@nablatherm.com \\ ${ }^{3}$ Institut de Recerca en Energia de Catalunya \\ Jardins de les dones de negre, 108930 Barcelona (Spain) \\ Phone/Fax number:+0034 625 615115,e-mail: acabot@irec.cat
}

\begin{abstract}
.
Thermoelectric generators (TEGs) have become a promising technology for vehicle exhaust heat recovery. In this paper, a novel prototype with reduced thermal inertia, low size and capable to withstand the exhaust highest temperatures has been proposed. A small-scale prototype has been built and tested for further study. Results of experiment show the reasonability for exhaust heat recovery. The prototype can generate a maximum power output of about $111 \mathrm{~W}$ when operating at exhaust temperatures of $700{ }^{\circ} \mathrm{C}$. The vehicle speed is a significant factor affecting the TEG performance for waste heat recovery. It can be found that the higher the vehicle speed is, the better the performance of the ATEG is. Also the temperature of the cooling system strongly affects the ATEG performance. Higher water cooling temperatures reduce temperature difference between hot and cold side of TEGs and cause a reduction on ATEG efficiency.
\end{abstract}

\section{Key words}

Automotive, Thermoelectric, Generator, Waste, Heat.

\section{Introduction}

Internal combustion engines waste through the tailpipe about the same amount of thermal power they produce mechanically, around $35-40 \%$ of the fuel energy supplied, even when operating at top efficiency[1-4]. It is therefore advantageous to recover a portion of this wasted energy by converting it into electricity[5]. This electric recovery will be especially useful in the case of vehicles having a high degree of electrification, synergistically increasing the efficiency potential.

A significant number of researches in cooperation with several vehicle manufacturers have been done for exhaust manifold, exhaust piping and catalytic converter packaging design for automotive exhaust system to improve performance based on heat transfer analysis of exhaust system. The most interesting results of this research have been described in Table I, which summarizes the achievements reported.

Bismuth Telluride is the most popular thermoelectric material. However, its use is limited because its maximum operating temperature is relatively low. As they are widely used and mass produced, their cost is low compared to other thermoelectric materials. Other materials and techniques have been used to improve the power generation and efficiency of TEGs. Due to the high temperatures achieved on the exhaust line, the most promising and practical materials to be used for TEGs in exhaust heat recovery systems would be materials rated for a high temperature. This means a larger temperature difference can be present and potentially more power and higher efficiency can be achieved. Lead telluride and calcium manganese have been used as materials in TEGs due to their ability to handle higher temperatures. Some TEGs have been manufactured with segmented material. A material with a high ZT at higher temperatures is used on the hot side (i.e.: lead telluride) and a material with a high ZT at lower temperatures is used on the cold side (i.e.: bismuth telluride). More power would be produced compared to a TEG made of just the high temperature rated material. Other materials such as skutterudites and other manufacturing techniques such as quantum well structures have been investigated to improve TEG power generation efficiency but they are still very expensive and not commercially available.

The objective of this study is to test and analyze the performance of a new concept of ATEG under different stationary regimes. This new thermoelectric generator 
makes use of a hot side heat exchanger geometry that reduce the thermal inertia and guarantees TE material will resist the highest exhaust temperature.

\begin{tabular}{|c|c|c|c|c|c|c|c|}
\hline Heat source & $\begin{array}{l}\text { ATEG } \\
\text { power }\end{array}$ & $\begin{array}{c}\text { Exhaust } \\
\text { Temperatures }\end{array}$ & $\begin{array}{l}\text { Cooling } \\
\text { temperature }\end{array}$ & TE material & $\begin{array}{c}\text { Exhaust } \\
\text { flow } \\
\text { rate }\end{array}$ & $\begin{array}{l}\text { Pressure } \\
\text { loss }\end{array}$ & Ref. \\
\hline $\begin{array}{l}\text { Cummins } \\
\text { NTC350 } 141 \\
300 \mathrm{HP} \\
\text { Diesel truck } \\
\text { engine }\end{array}$ & 1068 & - & - & BiTe & - & - & [6] \\
\hline Toyota 21 & 266 & 650 & 25 & Skutterudites/BiTe & - & - & [7] \\
\hline $\begin{array}{c}\text { Ruston } \\
\text { 3YDA 3,61 }\end{array}$ & 12,2 & 650 & - & BiTe & - & - & [8] \\
\hline $\begin{array}{c}\text { Ford Lincoln } \\
\text { BMW X6 }\end{array}$ & $700 \mathrm{~W}$ & 625 & $20 / 80$ & Skutterudites & $45 \mathrm{~g} / \mathrm{s}$ & - & [9] \\
\hline $\begin{array}{c}\text { Combustor } \\
\text { bench }\end{array}$ & 35,6 & 595 & 25 & $\mathrm{SiGe}$ & $58 \mathrm{~g} / \mathrm{s}$ & - & [10] \\
\hline $\begin{array}{c}\text { GMC Sierra } \\
5.31 \\
\end{array}$ & 177 & 550 & 88 & BiTe & - & - & [11] \\
\hline $\begin{array}{l}\text { Chevy } \\
\text { suburban }\end{array}$ & 235 & 600 & - & Skutterudites/BiTe & - & - & [12] \\
\hline $\begin{array}{l}\text { Engine } \\
\text { simulator }\end{array}$ & 350 & 600 & 10 & BiTe & - & - & [13] \\
\hline $\begin{array}{l}\text { Experimental } \\
\text { rig }\end{array}$ & 250 & 600 & - & Silicide & - & $<30 \mathrm{mbar}$ & [14] \\
\hline $\begin{array}{c}\text { Light Duty } \\
\text { Truck } 2.31 \\
\text { diesel engine }\end{array}$ & 500 & 450 & - & BiTe & - & $<30 \mathrm{mbar}$ & [15] \\
\hline
\end{tabular}

Fig. 1. Most significant ATEGs build and tested to date.

\section{ATEG}

The automotive thermoelectric generator (ATEG) presented in Fig. 2 is designed for exhaust pipes of automobiles. The purpose of these kind of systems is to turn the wasted energy into a useful one. In this case, into a source of electrical power, in order to feed many electrical parts of the vehicle, leading to fuel and greenhouse emissions savings.

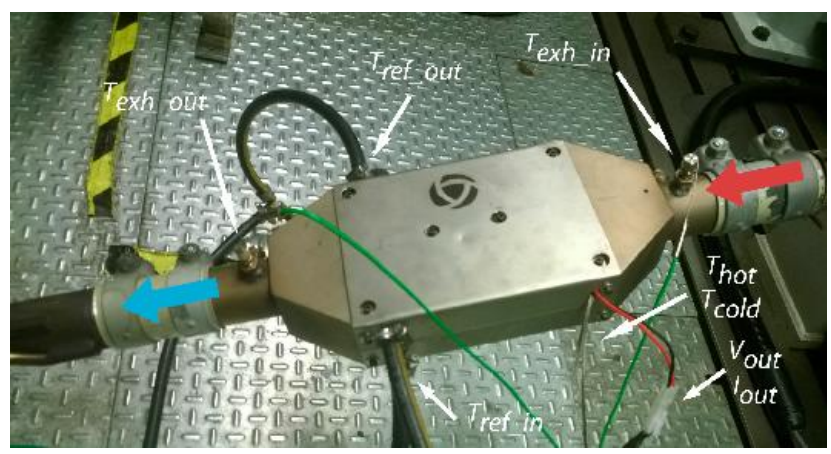

Fig. 2. ATEG installed on the engine exhaust.
The working mode is based on the conversion of heat into electricity. Thermoelectric materials generate a voltage while in a temperature gradient on their junctions. In such case, electrons flow from hot to cold by Seebeck effect.

A thermoelectric module (TEM) is a circuit containing two different thermoelectric materials. One, a negative charged semiconductor, called n-type, and the second, a positive charged semiconductor, called p-type. These two semiconductors form a thermoelectric couple. Then, concatenating several thermoelectric couples wired electrically in series a thermoelectric module is obtained.

The objective of this ATEG is to get a high temperature gradient on the both sides of the thermoelectric modules using the energy contained in the exhaust fumes of a combustion engine. The gases flow internally through the device and transfer a portion of its heat through the thermoelectric modules to the cold plates. Then, the cooling circuit, that uses water as a coolant, takes the heat and dissipates it using a forced convection exchanger. The more heat flows through the thermoelectric modules, the higher the power generated. 
The size of the device is $160 \times 500 \times 60 \mathrm{~mm}(\mathrm{WxLxH})$ with a total weight of $6,97 \mathrm{~kg}$. It is composed by 12 thermoelectric modules connected electrically in series but thermally in parallel. TEMs are constructed with Lead Tin Tellurium and Bismuth Tellurium and stuck with high thermal conductivity graphite sheet on their both sides to provide low contact thermal resistance. These modules are arranged on the both surfaces of a copper heat exchanger (2), through which the exhaust gas is passed, and two aluminum cold plates (3). Fig. 3 shows the schematic diagram of the experimental ATEG.

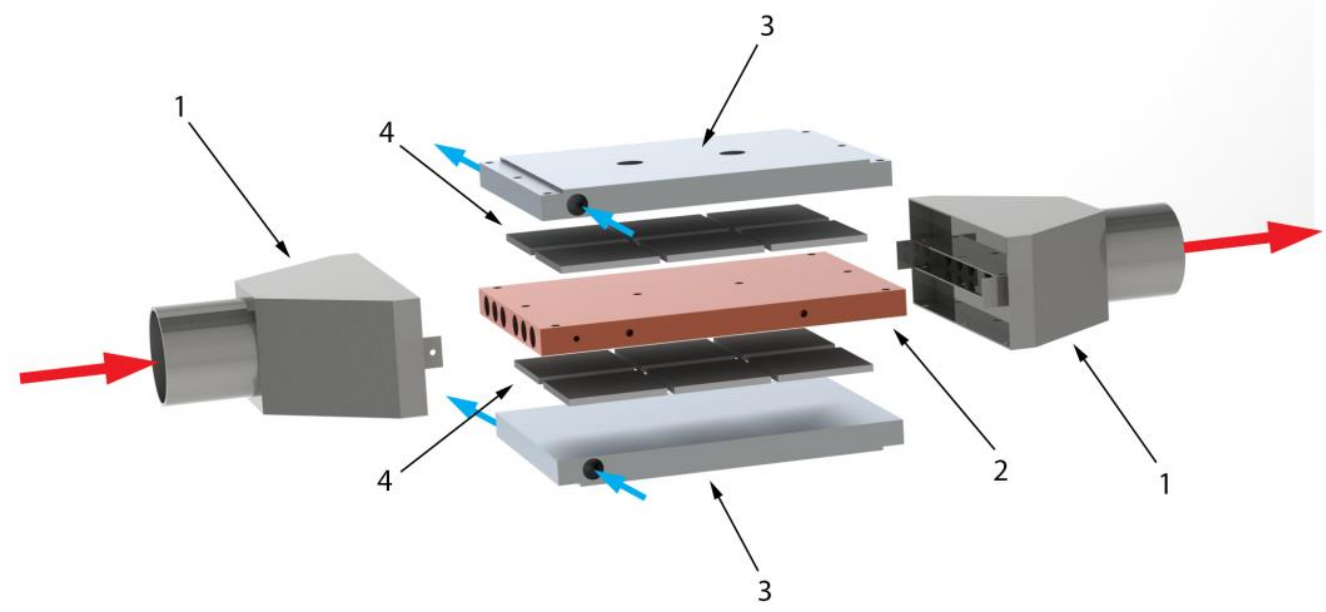

Fig. 3. Exploded view of prototype. 1) Exhaust fumes inlet and outlet. 2) Heat exchanger. 3) Cold plates. 4) Thermoelectric modules. In red, exhaust gases. In blue, cooling system's water.

\section{Results and discussion}

Fig. 4 to 9 shows the data obtained from the stationary study. On the whole, four stationary points were stablished: three standard engine regime points at 2000rpm and acceleration rate of $15 \%, 45 \%$ and $85 \%$, and a final point at maximum engine regime of $4000 \mathrm{rpm}$ and $85 \%$ of acceleration. It can be observed that all electrical parameters such as voltage in Fig. 4, current in Fig. 5 and power in Fig. 6 increase with the engine load.

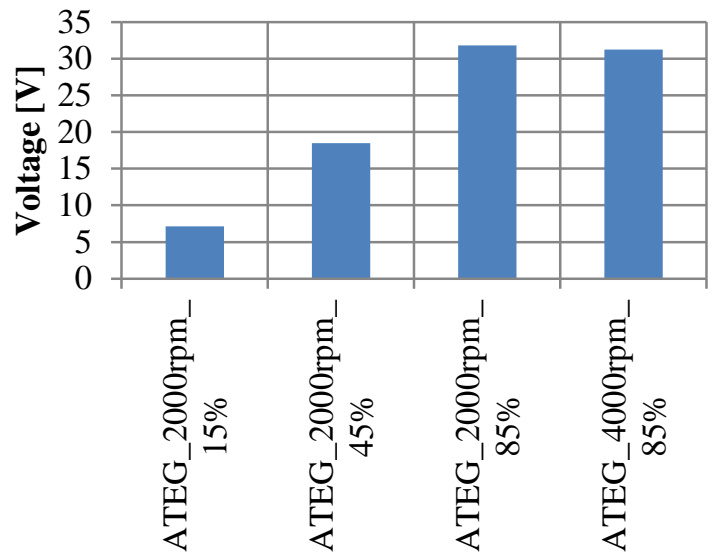

Fig. 4. ATEG voltage at MPP at various stationary regimes.

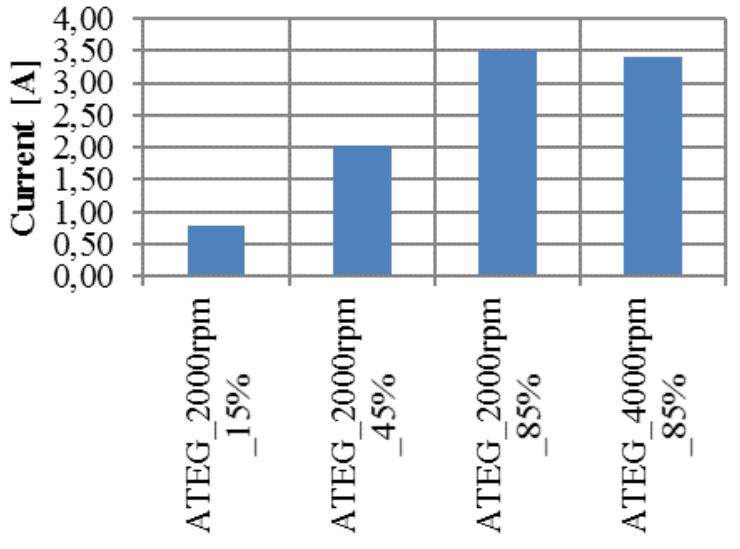

Fig. 5. ATEG current at MPP at various stationary regimes.

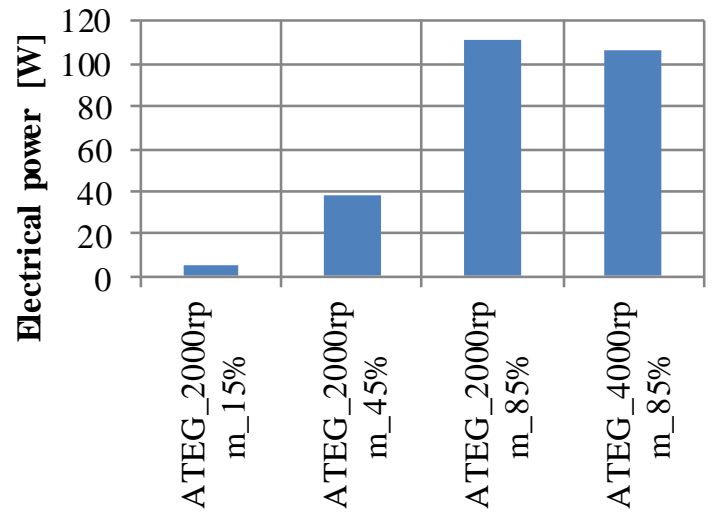

Fig. 6. ATEG electrical power at MPP at various stationary regimes. 
As can be seen in Fig. 7, the more the engine load, the higher is the exhaust gas temperature and flow rate and consequently, the more the power generated by the ATEG.

On the last stationary point, it can also be observed that, in spite of having a highest exhaust temperature, the power production is lower than expected. That is because of the higher temperature on the cooling system that causes a $\Delta T$ decrease on TEGs, Fig. 9. The exhaust temperature lost through the ATEG remain constant throughout all the tests.

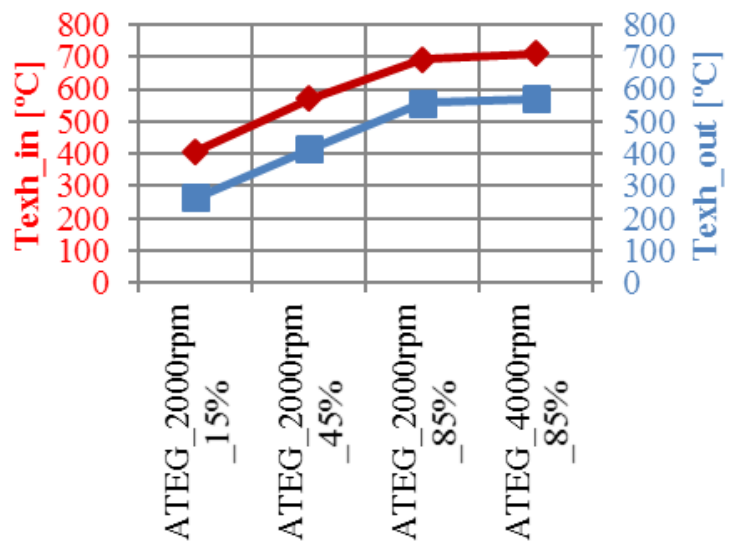

Fig. 7. ATEG inlet and outlet exhaust temperature at various stationary regimes.

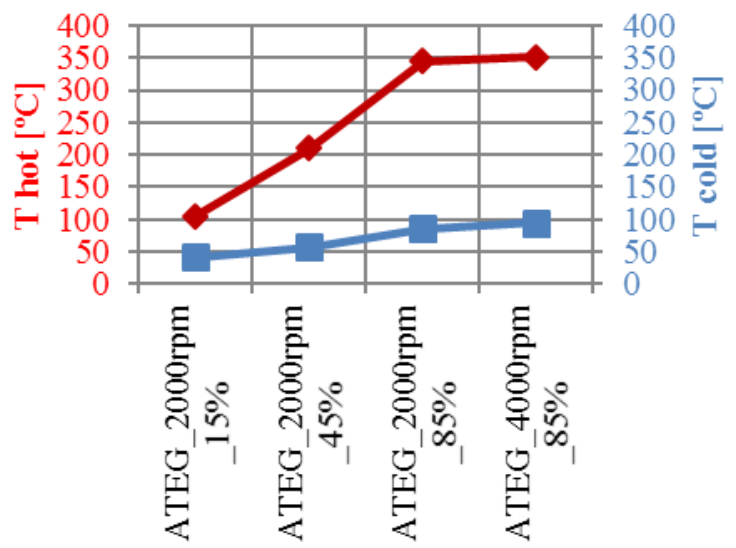

Fig. 8. TEGs hot and cold side temperature at various stationary regimes.

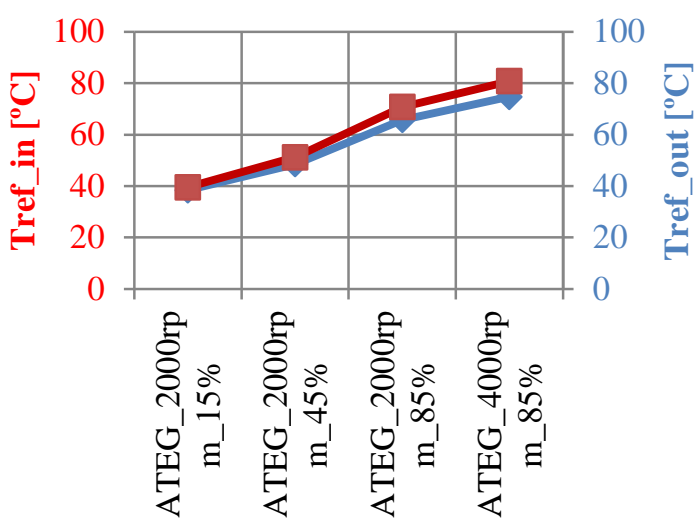

Fig. 9. ATEG inlet and outlet water cooling temperature at various stationary regimes.
Considering the data obtained from the experiments, the way in which the vehicles are driven is a significant factor affecting the ATEG performance for waste heat recovery. Most of the ATEGs developed in literature have been designed to withstand the maximum temperature of the exhaust gases. In this case, the ATEG was designed to withstand the maximum allowable temperature of TEGs, which was $350^{\circ} \mathrm{C}$ at $700^{\circ} \mathrm{C}$ of exhaust gases. Taking into account that during normal driving conditions this working point is rarely achieved, it can be stated that the majority of ATEGs will work below its MPP.

\section{Conclusion}

In this study, an automotive thermoelectric generator ATEG based on vehicle waste heat recovery has been developed. The ATEG system behavior is investigated for constant and dynamic driving conditions. It is found that the vehicle speed is a significant factor affecting the ATEG performance for waste heat recovery, the higher the vehicle speed is, the higher the temperature of the exhaust gases and the better the ATEG performance is. In stationary conditions, the maximum power output is $5.52 \mathrm{~W}$ at $2000 \mathrm{rpm}$ at $15 \%$ acceleration, and it reaches $111.22 \mathrm{~W}$ at $2000 \mathrm{rpm}$ at $85 \%$ acceleration. Transitory tests have demonstrated that the way in which the vehicle is driven is also a significant factor affecting the ATEG performance for waste heat recovery.

All ATEGs developed in literature have been designed to withstand the maximum temperature of the exhaust gases. However, during normal driving conditions this working point is rarely achieved. Additionally, the high thermal inertia of the ATEG prevent thermoelectric materials from achieving its MPP when it is subjected to transitory conditions such as present in a NEDC driving cycle. Consequently, the results suggest that the majority of ATEGs will produce significantly less energy than expected from stationary analysis. Highly frequent change of driving condition may have a negative effect on the ATEG performance. Only vehicles that work in a very constant regime such as high-duty vehicles will take advantage of this kind of energy harvesters.

\section{Acknowledgement}

This work has been partially funded by the University of Girona under grant MPCUdG2016-4.

\section{References}

[1] Y.Y. Hsiao, W.C. Chang, S.L. Chen, A mathematic model of thermoelectric module with applications on waste heat recovery from automobile engine, Energy. 35 (2010) 1447-1454. doi:10.1016/j.energy.2009.11.030.

[2] C. Su, N. Tong, Y. Xu, S. Chen, X. Liu, Effect of the sequence of the thermoelectric generator and the threeway catalytic converter on exhaust gas conversion efficiency, J. Electron. Mater. 42 (2013) 1877-1881. doi:10.1007/s11664-012-2454-2. 
[3] K.M. Saqr, M.K. Mansour, M.N. Musa, Thermal design of automobile exhaust based thermoelectric generators: Objectives and challenges, Int. J. Automot. Technol. 9 (2008) 155-160. doi:10.1007/s12239-0080020-y.

[4] T. Wang, Y. Zhang, Z. Peng, G. Shu, A review of researches on thermal exhaust heat recovery with Rankine cycle, Renew. Sustain. Energy Rev. 15 (2011) 2862-2871. doi:10.1016/j.rser.2011.03.015.

[5] A. Shabashevich, N. Richards, J. Hwang, P.A.

Erickson, Analysis of powertrain design on effective waste heat recovery from conventional and hybrid electric vehicles, Appl. Energy. 157 (2015) 754-761.

doi:10.1016/j.apenergy.2015.02.067.

[6] J.C. Bass, N.B. Elsner, F.A. Leavitt, Performance of the $1 \mathrm{~kW}$ thermoelectric generator for diesel engines, in: AIP Conf. Proc., AIP, 1994: pp. 295-298. doi:10.1063/1.46818

[7] K. Matsubara, Development of a high efficient thermoelectric stack for a waste exhaust heat recovery of vehicles, in: Twenty-First Int. Conf. Thermoelectr. Proc. ICT '02., IEEE, 2002: pp. 418-423.

doi:10.1109/ICT.2002.1190350.

[8] J.G. Haidar, J.I. Ghojel, Waste heat recovery from the exhaust of low-power diesel engine using thermoelectric generators, in: Proc. ICT2001. 20 Int. Conf. Thermoelectr. (Cat. No.01TH8589), IEEE, 2001: pp. 413-418. doi:10.1109/ICT.2001.979919.

[9] D.T. Crane, J. Lagrandeur, Thermoelectric Waste Heat Recovery Program for Passenger Vehicles. 2012 Vehicle Technologies Program Annual Merit Review, Present. Slide. (n.d.) 1-23..

[10] K. Ikoma, M. Munekiyo, K. Furuya, M. Kobayashi, T. Izumi, K. Shinohara, Thermoelectric module and generator for gasoline engine vehicles, Seventeenth Int. Conf. Thermoelectr. Proc. ICT98 (Cat. No.98TH8365). (1998). doi:10.1109/ICT.1998.740419.

[11] E.F. Thacher, B.T. Helenbrook, M.A. Karri, C.J. Richter, Testing of an automobile exhaust thermoelectric generator in a light truck, Proc. Inst. Mech. Eng. Part D J. Automob. Eng. 221 (2007) 95-107.

doi:10.1243/09544070JAUTO51.

[12] S. Kumar, S.D. Heister, X. Xu, J.R. Salvador, G.P. Meisner, Thermoelectric Generators for Automotive Waste Heat Recovery Systems Part II: Parametric Evaluation and Topological Studies, J. Electron. Mater. 42 (2013) 944955. doi:10.1007/s11664-013-2472-8.

[13] S. Kim, B. Won, S. Rhi, S. Kim, J. Yoo, J. Jang, Thermoelectric Power Generation System for Future Hybrid Vehicles Using Hot Exhaust Gas, J. Electron. Mater. 40 (2011) 778-783. doi:10.1007/s11664-011-1569. 1
[14] L. Aixala, RENOTER Project Introduction - Volvo Group, Thermoelectr. Appl. Work. (2011). http://energy.gov/eere/vehicles/downloads/renoterproject- 0 .

[15] D. Magnetto, M. Brignone, A. Ziggiotti, HeatReCar Thermoelectric Waste Heat Recovery in Light Duty Trucks optimal use of energy Consortium and main objectives, Present. Slide. (2010). 